\title{
The Relationship Between HIV/Sexually Transmitted Infection Risk and Alcohol Use During Commercial Sex Episodes: Results From the Study of Female Commercial Sex Workers in the Philippines
}

\author{
CHI CHIAO ${ }^{1}$, DONALD E. MORISKY ${ }^{2}$, RHONDA ROSENBERG ${ }^{3}, \mathrm{KATE} \mathrm{KSOBIECH}^{4}$, and \\ ROBERT MALOW ${ }^{3}$ \\ ${ }^{1}$ National Cheng Kung University, Tainan, Taiwan, ROC \\ ${ }^{2}$ University of California, Los Angeles, Los Angeles, CA, USA \\ ${ }^{3}$ Florida International University, Miami, FL, USA \\ ${ }^{4}$ Marquette University, Milwaukee, WI, USA
}

\begin{abstract}
The HIV/Sexually Transmitted Infection (STI) risk associated with alcohol use between female commercial sex workers (FCSWs) and their customers has been understudied. We examined this relationship for 1,114 FCSWs aged 15-54 with data collected during the baseline study period (1994 to 1998) in four southern provinces of the Philippines. Two alcohol-related risk situations during commercial sex episodes were examined: prior alcohol use by an FCSW and perceived intoxication in a customer. The influence of sociodemographic variables on sexual risk behaviors was also studied. Multiple sexual risk behaviors were observed with more frequency for FCSWs if alcohol was used before commercial sex or if the episode involved a customer perceived to be intoxicated. Forty-two percent of FCSWs who had sex with an intoxicated customer were STI positive, significantly more than FCSWs who did not have sex with an intoxicated customer (28\%, $\mathrm{p}<.01)$. Similar significant differences were found for FCSWs who did not consume alcohol before having sex and were STI positive (29\%) versus FCSW who did consume alcohol before sex and were STI positive $(33 \%, \mathrm{p}<.01)$. Our analyses reinforce accumulating evidence in the field that sexual risk reduction interventions need to go beyond the behaviors of individual FCSWs to meet the layering of risks such as observed in this study. Multilevel strategies targeting customer substance use and other situational and structural factors have proven to be pivotal mediators in our other research with this population. These experiences and the limitations of this study are discussed.
\end{abstract}

\section{Keywords}

environmental factors; female commercial sex workers (FCSWs); HIV; Philippines; sex workers (indirect, freelance); sexually transmitted infections (STIs); situational factors

Address correspondence to Dr. Donald E. Morisky, Department of Community Health Sciences at UCLA School of Public Health, 650 Charles E. Young Drive South, Box 951772, 26-070 CHS, Los Angeles, CA 90095-1772, USA. dmorisky@ucla.edu. 


\section{Introduction}

Throughout the world, governments are striving to initiate programs and confront the threat of HIV/AIDS. In India, perhaps somewhat belatedly, the government is now recognizing the importance of incorporating sociocultural and behavioral contexts in promoting the use of condoms as an HIV/AIDS prevention strategy even among heterosexual couples (Bhattacharya, 2004). In China, efforts are underway to encourage condom use by focusing on high-risk populations such as hospitality girls working in licensed entertainment establishments (Wei et al., 2004).

In the Philippines, where HIV/AIDS has not yet become a generalized epidemic (UNAIDS, 2003), the government is moving aggressively to confront the problem by instituting an action plan that emphasizes local responsiveness by governmental agencies and nongovernmental organizations, the incorporation of HIV/AIDS education into the school curriculum, and laws forbidding discrimination against persons with HIV/AIDS or those who belong to at-risk groups. Infection rates in the usual risk groups (e.g., sex workers, men who have sex with men, sexually transmitted infection [STI] clients, returning overseas workers) remain below $1 \%$ throughout most of the Philippines (Mateo et al., 2004) and up to $2 \%$ among registered female sex workers (UNAIDS, 2003). This low HIV incidence rate is often attributed to the relatively low number of full-time sex workers, the relatively low average number of clients per night, the low proportion of injectors among drug users, the early multisector response to the epidemic, and/or the establishment of social hygiene clinics for sex workers. A recent study by Du Mont and McGregor (2004) concluded that social and structural factors are involved in the decisions of female commercial sex workers (FCSWs) regarding medical examinations, even when required by law. However, rates of STIs, multiple sex partners, and injection drug use with needle sharing are increasing, suggesting that an explosive epidemic could still occur if the virus is introduced into key at-risk populations. One need only look to Vietnam and Indonesia to provide examples of delayed epidemics of HIV/AIDS; a similar trajectory could also occur in the Philippines (Mateo et al., 2004). In those countries, government inactivity and "denial" of the potential HIV/ADS problem in its infancy exacerbated problem situations and led to larger rates of infection in subsequent years.

Not surprisingly, early HIV prevention campaigns focused primarily on individual knowledge and attitudes in an effort to produce changes in personal behaviors that contribute to HIV risk (Catania et al., 1989). However, it has become increasingly evident that sustainable outcomes are more likely when interventions include multilevel and ecological components that reinforce individual-level changes (Bandura, 2004; Poundstone et al., 2004). Researchers have applied various theoretical structures, integrating situational determinants into individual-level targeted HIV behavioral interventions (Kelly et al., 1993). Although not formally acknowledged, many HIV prevention interventions have documented the success of situational and environmental factors as determinants of behavior (Fishbein, 2000; Kalichman et al., 1999; Melkote et al., 2000; Morisky et al., 2002; Nyamathi et al., 1995). Demographic variables, local resource constraints, familial and social support, institutional reinforcements, and public service linkages have all been implicated in affecting behavioral changes and have been increasingly examined and targeted by interventionists seeking more contextually oriented designs. These efforts echo ideas long expressed in other fields and disciplines (Tuan, 1974) that emphasize the "situated" nature of human populations and the consequent need for social ecological approaches to inquiry and policy action.

The most relied on HIV risk reduction strategy globally has been the promotion of consistent and correct condom use (Carlin and Boag, 1995), which is often the primary 
dependent variable (i.e., quantified measurable "outcome") in many studies (Fishbein and Pequegnat, 2000; Kuntolbutra, 1996). Condom use has been linked to many dispositional influences, including motivation, negotiation skills, sexual self-efficacy, knowledge of HIV transmission, and one's perceived risk of contracting HIV. As Auerbach and Coates (2000) have made explicit, however, the current state of HIV prevention intervention science encompasses more than protective technologies and behavior. Specific counseling, normative, social, and institutional strategies now exist to enable individuals and communities to make protective choices and act on prevention messages in their real lives. The situational and cultural barriers that these strategies address have moved the science of HIV intervention forward. Situational determinants clearly relate to condom use. They may include structural characteristics inherent in the environment, such as a pro-condom attitude in a sexually oriented workplace, an employer's positive attitudes toward condom use, consent of the sexual partner, and the availability/price of condoms.

In the Philippines, sex work is not legal. Nevertheless, establishment-based FCSWs are required by the government to register at local social hygiene clinics (SHCs) and to undergo weekly or bimonthly check-up appointments. Personnel from the City Health Office make unannounced visits to the various establishments in the community to validate that all FCSWs have a registration card on file. Owners and managers of establishments found not to adhere to this policy are fined, and after three violations the establishment is closed for 1 week (Morisky et al., 2002).

In the Philippines, FCSWs are employed in bars, nightclubs, disco houses, karaoke TV centers, and massage parlors. Employees in these establishments are most often called indirect sex workers rather than brothel-based or free-lance direct sex workers. Over a decade ago it was estimated that there were more than 225,000 registered establishmentbased FCSWs in the Philippines (Tan, 1993). Abellanosa and Nichter (1996) have reported that FCSWs who remain unregistered at a SHC are seven times less likely to use condoms with their customers than registered FCSWs and tend to have sex with three times as many customers than their registered counterparts.

Establishment-based FCSWs often work under conditions that promote condom use between customer and client (Albert et al., 1995; Pyett et al., 1996). Commercial sex work establishments thus serve as the situational context for condom use norms and practices of FCSWs. Previous interventions with establishments (brothels) in Indonesia and Thailand have led to increased condom use among FCSWs (Ford et al., 1996; Visrutaratna et al., 1995). Our prior research also identified establishment policies as an important factor influencing condom use among FCSWs (Morisky et al., 1998; Tiglao et al., 1997). As a situational determinant, alcohol use might well induce a variety of risky sexual behaviors in the FCSW and/or the customer. However, research on alcohol use and unsafe sex has failed to document a consistent relationship.

Findings from such research, primarily with men who have sex with men, indicate that personality and contextual factors may mediate this relationship (McKirnan et al., 1996; Mutchler, 2000; Weinhardt and Carey, 2000), highlighting a need for qualitative analyses of the diverse roles that alcohol consumption plays in the sexual practices of men who have sex with men. For men who have sex with men, alcohol use may facilitate behaviors that would otherwise elicit shame or guilt based on internalized social norms and proscriptions. Alcohol consumption and sexual behaviors may become so intertwined for some individuals that there is great difficulty in performing sexually when sober.

Although some studies document a significant relationship between alcohol use and risky sexual behaviors among HIV-infected men, others have not (Variable et al., 2004). A recent 
systematic review of the relevant literature failed to find evidence of a direct link between alcohol use and risky sex (Weinhardt and Carey, 2000). Although alcohol consumption has not been consistently linked to unsafe sex in a causal manner, some researchers have reported that alcohol intoxication influences contextual factors related to sexual risk activities (McKirnan et al., 1996; Mutchler, 2000; Parsons et al., 2004). Specifically, alcohol use may focus attention on the present context, blunting awareness of prevailing social norms or an individual's own code of acceptable behavior (Steele and Josephs, 1990). Alcohol use may also impact one's normal behavioral self-monitoring while subsequently exacerbating the potential influences of environmental stimulations. Further, the expectancies from the effects of alcohol may synergize risky sex among HIV-infected men if the assumption is made that prompting alcohol use will positively affect their sexual experiences (Kalichman et al., 2002). Just as Zinberg (1984) made the field sensitive to considering the interaction of set, setting, and drug use with regard to a "drug experience," so too can different endogenous and exogenous factors (different types of partners, types of sexual acts performed, types and levels of risk taking, and whether or not condoms are used, etc.) and their interactions influence HIV/STI among commercial sex workers who consume alcohol.

This study used an ecological perspective to analyze putative personal and situational influences of alcohol use among FCSWs and their customers in the Philippines. Specifically, we focused on the impact of alcohol consumption by FCSWs and their customers before the commercial sexual episode. Causal modeling was used to examine the psychosocial predictors (a term that implies both personal and situational influences) of AIDS risk behaviors similar to Nyamathi et al. (1995) and Stein and Nyamathi (2000). Personal factors included the FCSWs' individual sexual health risks, perceived susceptibility to HIV, and alcohol and drug use-related behaviors. Situational factors were operationalized as establishment and/or manager policies concerning condom use policies between sex worker and client as well as other structural characteristics inherent in a woman's situation, such as exposure to AIDS education efforts. Situational as well as personal influences were hypothesized to be operating among women clustered within establishments. This study also sought to assess the extent to which socioeconomic groups, psychosocial traits, and sexual practices were related to situational influences, including a FCSW's situational alcohol use behavior.

\section{Methods}

\section{Study Population}

From the outset, an advisory task force at each intervention location was organized through the University of the Philippines, College of Public Health. Advisory committee members consisted of the Regional Health Officer, City Health Officer, representatives from the Mayor's Office, representatives from the local HIV/AIDS organizations (both private and public), community leaders, and representatives from the establishments participating in the study. Meetings were held quarterly throughout the duration of the investigation. All these individuals, as well as the FCSWs who agreed to participate, were made aware of the benefits that might accrue via a scientific evaluation of the type and prevalence of STIs in the Social Hygiene Clinic and the possible future distribution of educational materials developed during and after the completion of the study.

Women were recruited from entertainment-related establishments on four southern Philippine islands, southern Luzon, Cebu, Ilo-Ilo, and northern Mindanao, from 1994 to 1998. Approximately $98 \%$ of the women provided informed consent after receiving culturally sensitive and appropriate human subjects protection information regarding the study and protocol (e.g., objectives, potential risks, and benefits) approved by UCLA and 
the University of the Philippines. Of 1,360 women interviewed, the data of 76 were excluded from our analyses because they denied commercial penetrative vaginal, anal, or oral intercourse. The sample size was further reduced to 1,114 by excluding an additional 170 women who denied any alcohol consumption.

Table 1 displays the sample's sociodemographic characteristics. The FCSWs averaged 23.5 years of age (range, 15-54), 8.96 years of schooling, and 12.47 months of sex work employment, with a mean weekly income of 1237.32 pesos (approximately $\$ 48.83$ a week in U.S. dollars, and the average per capita income in the Philippines was $\$ 952.98$ a year in U.S. dollars). Eight percent of the FCSWs were street workers, 67\% bar workers, and 30\% nonbar workers. Seventy percent reported they were unmarried or lived separately from their husbands. FCSWs reported often consuming alcohol, albeit less frequently with their customers, and seldom used other illicit substances, particularly injection drugs (4\%). Fully $19 \%$ had consumed alcohol before commercial sexual encounters, and $37 \%$ reported engaging in sexual acts with inebriated customers. FCSWs reported an average of two vaginal intercourse acts in the week before the interview. From a medical record review, it was found that $31 \%$ of the FCSW sample was ever infected with an STI and 14\% experienced STI reinfection during the 8-month investigation period.

\section{Major Measures}

Table 2 provides a description of measurements used in this study. STI prevalence was determined by the local SHC physicians who examined FCSWs. The STI prevalence measure displayed in Table 1 was coded by the research assistant: 1, infection present during 8 months of data collection; 0 , no infection present; and 8 , infection status unknown.

Alcohol use was assessed during transactional intercourse via asking FCSWs whether they ever drank alcohol before sexual contact with customers and whether they ever had sex when customers were perceived to be intoxicated. On a five-point Likert scale (never to always) FCSWs were also asked, "How often do you have beer or drinks containing alcohol?" and "How often do you drink beer or alcohol with your customers?"

Drug use was measured through a five-point Likert scale (never to always) item, "How often do you take drugs like marijuana, cocaine, or amphetamines?" and an item, "Have you ever injected a drug by sticking a needle into your arm?" Affirmative responders to the latter were further asked, "How often do you use injectable drugs?"

Condom use was assessed by six 5-point Likert scale items pertaining to how often FCSW "used a condom when engaging in vaginal sex," "whether they suggested using a condom to their partner," and "carry a condom on their person." In our prior work (Morisky et al., 2002a), the scale showed an alpha reliability of .80. After reverse-coded adjustments were made, responses were summed, with higher scores reflecting a greater likelihood of using condoms. FCSWs were also asked, "In the past month, have you had a condom fall off inside you?"

Other measures were derived from asking FCSWs about perceived HIV/AIDS risk and practice. For example, a five-point Likert scale question assessed a FCSW's level of worries about HIVAIDS: "How worried are you about getting AIDS?" Entertainment establishment managers were surveyed about AIDS education provided by their establishment including a dichotomous item on whether an education workshop operated within their establishment. Additional data were also gathered regarding the attitudes and behaviors of managers/ owners and supervisors as well as the FCSWs perceptions of the manager's attitudes, beliefs, and support provided when negotiating type of sex with the customer. These data are not the 
focus of the present investigation and therefore are not discussed further in the present article.

\section{Data Analysis}

Using Stata-PC version 8.0 software (StataCorp, 2004), data analyses explored the risk factors in two specific situations that involved alcohol use proximal to sexual contact. Bivariate analyses with chi-square tests for categorical variables and $\mathrm{F}$ tests for continuous variables were used to examine the distribution across the subgroups of these two specific alcohol use circumstances and determine the statistical significance of all comparisons (individual sociodemographics, sexual activity, and structural factors) from the selected subgroups.

We also explored whether a proposed ecological model could predict various alcohol use behaviors before sexual contact. Given categorical dependent variables with three levels, we used multinomial logistic regression with robust estimates to evaluate this model while adjusting for the cluster effect of workplace. For an outcome variable with three levels, two sets of contrasts were performed as well with the Wald test for each predictor. For example, in the first selected situation, the first contrast was comparing FCSWs reporting alcohol intake before sex with customers with those who did not. In the second contrast, FCSWs who reported not having sex with customers after alcohol intake were compared with those who did not respond to the item.

\section{Results}

\section{Background Information}

We analyzed the relationship between unsafe sexual behaviors and alcohol use in one risk situation defined by whether the FCSW ingested alcohol before commercial sex and a second risk situation distinguished by whether a customer was reported "drunk" by the FCSW. As displayed in Table 3, we found sociodemographic differences pertaining to age, education, and weekly income. FCSWs having sex with inebriated customers were older, earned higher wages, and worked for longer periods as sex workers than FCSWs who reported having alcohol intake before commercial sex. FCSWs who reported having sex with intoxicated customers were more likely to be street workers or non-bar-based employees than those who did not $\left(\chi^{2}(4)=129.04 ; p<.01\right)$.

\section{STI Status}

There was a clear contrast between the two situations previously described with respect to the STI status of FCSWs, with the second situation emerging as the most dominant. Using an 8-month interval, 31\% of FCSWs reported being diagnosed with an STI by a trained medical professional. As displayed in Figure 1, this STI rate was significantly higher among the FCSWs who reported having sex with an intoxicated customer (42\%) than those who did not (28\%) but was not associated with the likelihood of whether or not alcohol was used by the FCSWs before sex. An additional significant finding was that 33\% of FCSWs who reported alcohol intake before sex with a customer acquired STIs versus $29 \%$ of those who denied alcohol intake before sex.

\section{Sexual Risk and Alcohol and Drug Use}

Table 4 presents data for the two specific alcohol use circumstances reported by FCSWs. As displayed, those who drank alcohol before engaging in commercial sex were drinking alcohol with their customers more often, using illicit drugs more frequently, and engaging in more sexual activity than the nondrinking alcohol categories in risk situation 1. In risk situation 2 the FCSWs who had sex with an intoxicated customer were also more likely to 
use drugs and had higher rates of sexual activity compared with those FCSWs who did not have commercial sex with an intoxicated customers or did not respond the question. In addition, these groups of FCSWs were more likely to report that the condom fell off during commercial sex, even as a more frequent use of condoms was reported.

\section{Ecological Model Predicting Alcohol Use With Commercial Sex}

Risk Situation 1-The ecological models predicting alcohol use in the first commercial sex situation were statistically significant: Wald $\chi^{2}{ }_{(28)}=332.35(p<.01)$. Table 5 presents the first contrast, comparing FCSWs who had alcohol intake before commercial sex with those who did not have alcohol intake before commercial sex (reference group). FCSWs' alcohol and drug use significantly differentiated the group membership of this first contrast, such that FCSWs who used alcohol and drugs more frequently were more likely to drink alcohol before commercial sex. The FCSWs who did not have an HIV test were more likely to consume alcohol before commercial sex as opposed to the reference group. Those who used condoms were far more likely to drink alcohol with a sex customer in comparison with those who did not drink with the customer, whereas those who used condoms were far more likely to be nonrespondents on alcohol use question. Workplaces also predicted group membership: Street workers were more likely to drink alcohol before commercial sex as opposed to the non-bar workers.

In the second contrast of risk situation 1, FCSWs who did not respond to the alcohol consumption question were compared with those who did not consume alcohol before commercial sex (reference group). The education level of FCSWs was significant, suggesting that higher educated FCSWs were less likely to respond to this question. FCSWs' alcohol and drug use significantly differentiated the group membership, such that FCSWs who used drugs more often but drank alcohol with customers less frequently were more likely to be in the groups that did not respond to the question. Perceived AIDS risk was also a significant predictor: FCSWs with lower AIDS awareness were less likely to respond to the question. Relative to non-bar workers, street workers were more likely to be in the group that did not have a response as opposed to the reference group.

Risk Situation 2-The ecological models predicting alcohol use in the second commercial sex situation were statistically significant: Wald $\chi^{2}(28)=309.72(p<.01)$. In Table 6 , the first contrast found that sociodemographics significantly differentiated group membership, such as income and length of work. FCSWs who worked longer were more likely to have sex with intoxicated customers as opposed to those who did not have sex with intoxicated customers (reference group). The FCSWs who reported higher rates of drug use were more likely to be in the groups that had sex with intoxicated customers. HIV/AIDS perception and practice were also significant between the groups, suggesting that the FCSWs who did not have an HIV test or those with lower perceived risk of acquiring HIV were more likely to engage in sex with intoxicated customers compared with the reference group. Relative to establishment-based (bar or non-bar) workers, street workers were also more likely to have sex with intoxicated customers as opposed to the reference group.

In the second contrast for risk situation 2, education level and work duration of FCSWs was found to be significant, suggesting that higher educated or more experienced FCSWs were less likely to respond to the alcohol consumption question. FCSWs who reported drinking with customers were more likely to report having no sex with intoxicated customers compared with those who did not respond. HIV/AIDS perception and practice were also significant: The FCSWs with lower perception or those who did not have a HIV test were less likely to respond to the question as opposed to the group that responded having no sex with intoxicated customers. 


\section{Discussion}

Our analyses focused on how alcohol use influenced HIV/STI risk in the context of commercial sex activities. Currently, there is a lack of information regarding alcohol's influence on risky sexual behaviors for FCSWs. Even less is known about the influence of alcohol use by FCSW customers on unsafe sexual behaviors. Given that the FCSW/customer dyad is important in this circumstance, FCSWs who are at risk because they have sex with multiple paying and intoxicated customers confront different behavioral change issues than women not in the commercial sex trade (Poundstone et al., 2004). The current study built on our previous work with FCSWs (Morisky et al., 2002c) linking personal and situational factors as pivotal determinants of sexual risk behaviors.

Overall, this sample of FCSWs displayed a confluence of characteristics suggesting a significantly elevated risk of HIV/STI transmission. Although most acknowledged an increased susceptibility to HIV infection, this did not deter many from engaging in unsafe sexual practices. It is likely that these FCSWs experienced difficulty in implementing safer sex. About half of the sample indicated that they lacked confidence to propose condom use to their customers and were reluctant to refuse intercourse if a customer declined to use a condom. Research has documented that FCSWs tend to acquiesce to customer demands for noncondom sex, if doing otherwise would translate into loss of financial support (Wee et al., 2004).

Although risk reduction strategies often emphasize decreasing the number of lifetime sex partners along with other safer sex strategies, these behavior changes might be especially difficult for FCSWs, given such changes might well threaten their social and economic survival. Consequently, the most effective sexual risk reduction interventions may be those that include customers/clients along with mechanisms at the establishment level to support condom use. Likewise, HIV interventions might be designed to set establishment policy discouraging or prohibiting alcohol use by FCSWs and their customers while also enhancing client awareness of their susceptibility to HIV infection, thus encouraging use of condoms and other safer sexual methods. Unfortunately, in a transactional sex culture where safe sex is rare, condom use may not be easily accepted.

Intervention efforts could also be designed for the male customers to encourage more responsible preventive options (i.e., use of condoms, nonpenetrative sex, body massages to orgasm). Their success, however, would require "deep-rooted" changes in society's attitudes toward sex and masculinity (Foreman, 1998). This approach emerges from broader issues surrounding gender relations that have come to the forefront in recent years, in addition to those involving HIV/AIDS. Clearly, HIV prevention interventions must be developed in a manner acutely sensitive to the needs of each gender to make a significant impact on behavior change.

Behavioral interventions based on social psychological principles have yielded strategies that can decrease new HIV and STD infections (O'Leary et al., 2003). Roger (1983) emphasized the central importance of interpersonal network influences on individuals in convincing them to adopt new innovations. In the history of our work in the Philippines, opinion leadership was an important theme in the design and implementation of intervention strategies at the community level, beginning with the advisory committee and continuing with key personnel from the City Health Office, SHC, and establishment managers. This perspective is based on the recognition that HIV transmission is caused by processes at both the individual and societal levels, all of which affect individual behavior and rates of transmission (Poundstone et al., 2004). Most intervention approaches are directed at the individual level, addressing personal issues of knowledge, risk perception, self-efficacy, or 
drug abuse (Murphy et al., 2001). The recent Consensus Development Conference on Interventions to Prevent HIV Risk Behaviors (NIAAA Structural RFA, 2004) called for increased efforts in environmental and structural approaches for HIV prevention. Our results support this suggestion.

However, it is also important for future HIV risk reduction efforts to incorporate conceptual models that go beyond the intrapersonal cognitive-behavioral or individualistic framework and incorporate systemic/contextual mechanisms, emphasizing not only content but processes. This social ecology of the epidemic has been elaborated (DiClemente and Wingood, 2000, 2003; Morisky et al., 2002b; Poundstone et al., 2004; Wingood and DiClemente, 2000). The 2004 annual thematic issue of Epidemiologic Reviews was devoted to this shift of focus in several topical areas, including HIV/AIDS (Ibrahim, 2004). As noted by Morisky et al. (2005), because transactional FCSW/client sexual behavior occurs in an interpersonal/organizational context, organizational norms may indirectly support or discourage risky behavior. Morisky et al. (2005) stress that individual-oriented change procedures need to account for social contextual factors to be maximally effective. For example, emphasizing only the cognitive aspects of behavior change, such as belief in the benefits of condom use, belief in the severity of HIV/AIDS, or beliefs in personal vulnerability of HIV infection, is not sufficient to put the preventive action into place. One requires reinforcements outside the individual, such as manager support, peer reinforcement, and acquisition of specific skills (communication and negotiation of sexual behaviors). This was demonstrated by intervention outcomes in which changes in social support and other network factors were associated with reductions in HIV risk behaviors. Such data suggest that HIV prevention approaches based solely on changes in personal behavior may have limited impact if systemic/contextual influences (i.e., peer, poverty, and societal factors) are ignored (Morisky et al., 2005).

Finally, it should be recognized that considerable cultural variation exists within the entertainment establishment. Many factors, including degree of acculturation, socioeconomic and educational levels, gender, and age, must be considered in judging the appropriateness of prevention interventions for any given circumstance. Thus it is important to determine how closely individuals or groups that are targets of prevention interventions adhere to the values, beliefs, and practices attributed to the Filipino community as a whole. For example, the educational level is higher among FCSWs employed in the karaoke TV Centers and educational materials conceptualized and developed by these individuals (such as brochures and posters) were used in the project. Female bar workers and FCSWs employed in beer gardens and disco houses had lower educational levels, prompting the use of small group dynamics to make educational interventions more interpersonal.

Religion plays an important role in the lives of FCSWs, and most claimed to have a strong belief in God. Aware of the prohibitions imposed on their profession, FCSWs admitted feeling guilty or sinful, seldom attending mass or church as a consequence. However, birthdays are extremely important, and almost all indicated that they attend mass on this day. Consequently, local priests from the communities who had more open views of the needs of FCSWs and the importance of condom use for preventing HIV/AIDS were invited to training programs. Their understanding of the dilemma experienced by the FCSWs allowed them to talk openly on the importance of health, family, and attending to children's needs. Their participation had a profound impact on reducing the level of guilt and dissonance among FCSWs. Additional institutional reinforcements were sought by forming community partnerships with local health offices, SHCs, and the University of the Philippines.

In our model of situational and environmental influences on condom use, customer intoxication was a situational determinant of condom use. Alcohol use among commercial 
sex workers represented a personal determinant of condom use. HIV prevention at its best would attempt to encompass both realms. Our results indicate it is particularly important to focus on the situational determinants exerting an influence on condom use (i.e., to ensure that client intoxication does not contribute to HIV risk).

These findings correspond with our previous research showing the importance of going beyond individual determinants with HIV risk reduction interventions (Morisky et al., 2002c). In that article we concluded that personal determinants of condom use (such as condom attitudes) provide important information for constructing any particular intervention; however, that conclusion does not mean that situational determinants (e.g., client intoxication, FCSW drinking) can be ignored as interventions are developed, tested, and subsequently adopted. The results of the current study provide strong positive support for organizational-level strategies within FCSW establishments to discourage having customers who are intoxicated or using alcohol to reduce riskier sexual behaviors, such as prolonged vaginal or anal sex episodes to reach orgasm. This is what is often described as a structural approach to prevention and would involve training establishment managers in the effects of alcohol-related increases in the transmission of sexually transmitted diseases (STDs) and how to communicate with their employees regarding these risks. We believe the results of this study point to unaddressed risk increases influenced by alcohol-related factors, stressing the importance of targeting such situations in intervention activities.

Research conducted in Thailand has already demonstrated the value of using structural intervention approaches, including a mass condom promotional campaign and a $100 \%$ condom use program instituted in brothels in northern Thailand. This combined approach resulted in more than a sixfold increase in the percentage of condom use, from $14 \%$ to over $90 \%$ in a 4-year period, with a concomitant decrease of $85 \%$ in male STD cases (Hanenberg et al., 1994). Similar approaches are being incorporated in the Philippines project, with educational policy conceptualized as a continuum from meeting regularly with employees to providing condoms and educational materials, mandating 100\% condom use among employees. Intermediate educational policy activities include encouraging attendance at the social hygiene clinic, providing an insurance fund for STD prescriptions, promoting AIDS awareness in the establishment, and making condoms available to customers (Morisky et al., 2005).

These policies have succeeded because stakeholders (government, managers, commercial sex workers (CSWs), clinics, and other interested groups) have been willing to put aside their individual goals and focus on the greater good for all. Cooperation between and across a wide assortment of groups with varying goals, beliefs, and philosophies has been the key to success. As a result, in nations such as Thailand and the Philippines, there has been steady progress in the fight to control the spread of HIV/AIDS. Despite alternative cultural influences, such as the Catholic Church's choice of abstinence over condom use, these prevention strategies have continued to be integrated. Given the diverse and sometimes oppositional normative values that can exist in these countries, self-esteem enhancement may be especially important in providing further impetus and confidence in the use of condoms (Nyamathi et al., 1995).

Our baseline analysis provides compelling support for a dual approach to encouraging safe sex behaviors for women operating as FCSWs in commercial establishments. It is hypothesized that a combined intervention with FCSWs and managers in such establishments will result in higher levels of knowledge and awareness as well as more positive attitudes toward condom use and a higher degree of actual condom use than interventions targeted at personal or situational factors alone. Further research would be beneficial to determine specific knowledge gaps regarding risk behaviors, testing patterns, 
and HIV incidence and prevalence in FCSWs. This research would be most valuable if it also included broader contextual factors that influence the lives of FCSWs and their risks for HIV infection.

Our prior research with this population has underscored that FCSW establishments are malleable institutions and that a combined intervention with FCSWs and managers has maximized condom use, reducing unprotected sex and STIs (Morisky et al., 2005). An important aspect of this research in guiding future policy was to delineate the most potent variations in implementing a situational/structural intervention with FCSWs. Among their recommendations for the next frontier of HIV prevention intervention research, Coates and Collins (1998) state that we "must identify impediments to implementation of HIV prevention strategies and collect empirical data to repudiate or support those impediments" (p. 323). This is a crucial criterion for future research because it exposes untested assumptions often held about groups, institutions, and countries that lead to a subtle stigmatization in which change is thought to be impossible or too costly.

FCSWs and their clients are examples of high-risk subgroups often excluded in the design of interventions, even when seeking to close the gap between research and practice.

Admittedly, they frequently are included in preliminary focus group studies yet rarely are enlisted in mutual partnerships with researchers beyond the needs assessment phase. An important experimental focus of our intervention work in the Philippines has been to push the boundaries of what is considered possible in the partnership between these groups and researchers. In practice, this has meant involving FCSWs and clients in the conceptualization of an intervention, its materials and implementation, and also its evaluation and interpretation of results (Morisky et al., 2004b, 2005). Traditionally, this has been called participatory action research; others prefer to define it as peer-driven designs or "bottom-up" instead of "top-down" approaches. Its basis is not merely an awareness of social or political stigma, but is an acknowledgement of the intellectual stigmatization that can pervade academic research institutions. Both types of stigmatization are deadly-not only to the life possibilities of vulnerable populations, but also to the possibility of the very innovations hoped for in HIV/AIDS prevention science.

Castro and Farmer (2005) effectively illustrated the life and death consequences of HIV/ AIDS-related stigma, which can emanate from the full spectrum of a country's stakeholders. The most notable example in news headlines pertains to the distribution of antiretroviral medications and concerns about the capacity for strict adherence among high-risk groups as well as populations in the developing world. These concerns have been repeatedly dispelled (Chesney, 2000), even in places thoroughly ravaged by the epidemic, such as Haiti. Castro and Farmer note that people in these countries can recognize what works the same as other populations and point to the high adherence rates in their programs in Haiti, which have depended not only on good drugs but also on good services and linkages. Their critique is that researchers and policymakers must guard against taking refuge in stigma, and even the study of it, if this distracts from the very real failure to find workable interventions and system-level solutions for groups and populations unable to break free of the epidemic. The lesson from our work in the Philippines is that the skills to be imparted to reduce HIV transmission are not unidirectional, flowing from expert to population target. Structural interventions must be multidirectional as well as multilevel. These are the innovations that we are waiting for and that behavioral and social scientists must find ways of making testable. 


\section{Acknowledgments}

This research was supported by grant R01-AI33845 from the National Institutes of Allergy and Infectious Diseases to Donald E. Morisky. We extend appreciation to co-investigator Teodora Tiglao; research managers Daisy Mejilla and Charlie Mendoza; and site coordinators Dorcas Romen, Mildred Publico, Angie Casas, and Lolipil Gella.

\section{Biography}

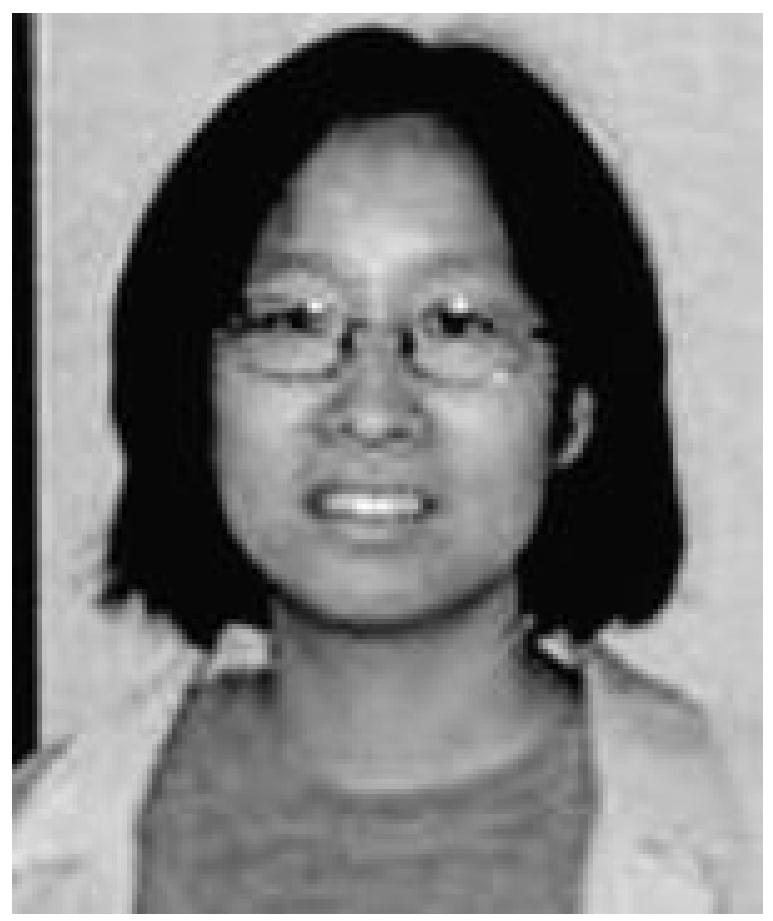

Chi Chiao, Ph.D., is Assistant Professor in the Department of Public Health, National Cheng Kung University, in Tainan, Taiwan. Her primary research interests are to investigate the demographic and social processes that influence sexual health-related behaviors of women. Her current work is exploring how sexual behaviors among sex workers are shaped by contextual factors by using multilevel approach.

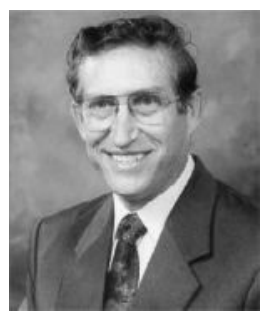

Donald E. Morisky, Sc.D., is Professor in the Department of Community Health Sciences, UCLA School of Public Health. He is a distinguished fellow in the American Academy of Health Behavior and the Society for Public Health Education. His research interests address the psychosocial and behavioral determinants of chronic (high blood pressure, diabetes) and infectious diseases (tuberculosis, HIV/AIDS) and focus on the behavioral construct of adherence to medical recommendations. He has directed his research to the design, implementation, and evaluation of community-based educational interventions using interpersonal and sociostructural/environmental approaches to behavior modification. 


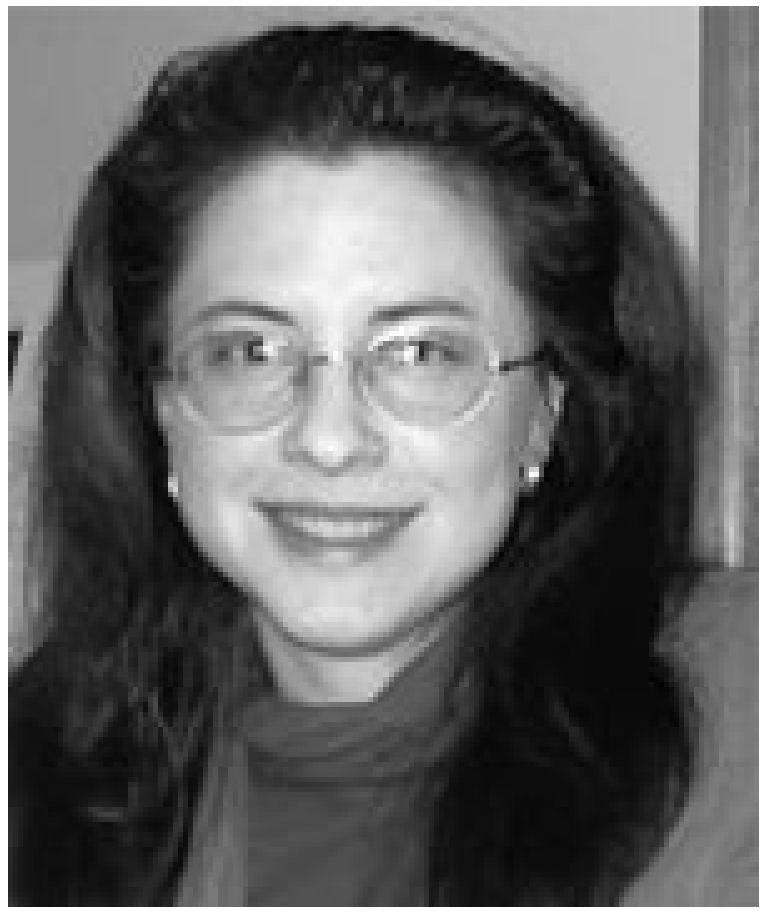

Rhonda Rosenberg, Ph.D., is Research Assistant Professor in the AIDS Prevention Program in the Stempel School of Public Health at Florida International University in Miami, Florida. She has published in screening and cost/benefit issues of alcoholism prevention in primary care and in HIV/AIDS prevention and intervention design. Her research interests are in the affective determinants of HIV/AIDS risk and the interactive elements of intervention design. A major interest is the critique and advancement of structural approaches, including the emerging research on social and natural capital as contextual factors in emerging infectious diseases. 


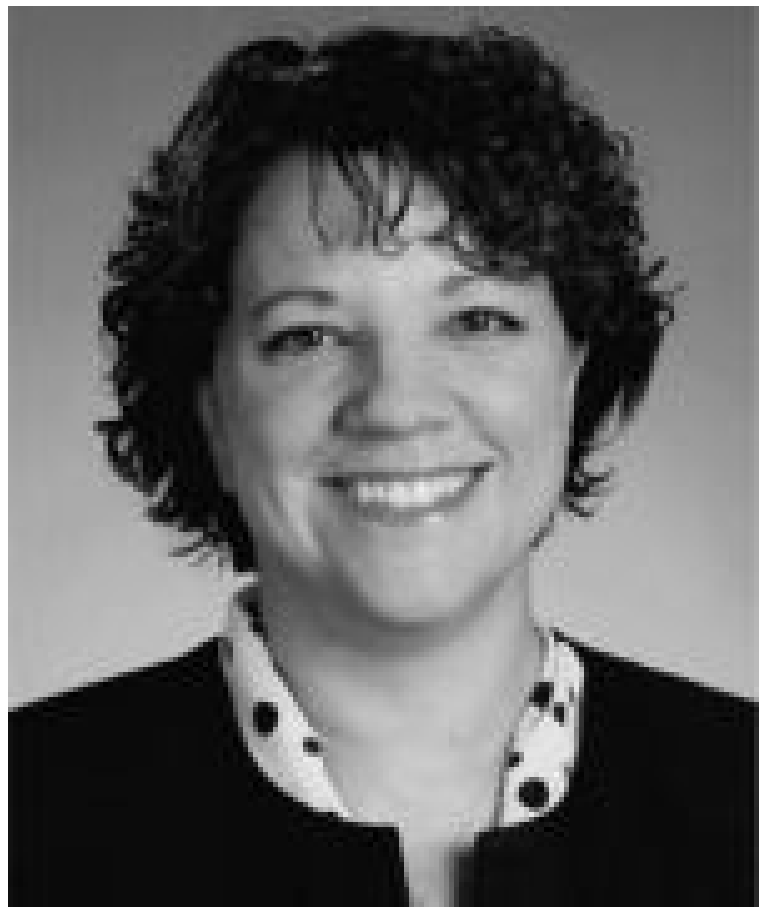

Kate Ksobiech, Ph.D., is Visiting Assistant Professor at the J. William and Mary Diederich College of Communication, Marquette University in Milwaukee, Wisconsin. Her research interests focus on HIV prevention interventions, particularly those geared toward injection drug users. She conducted a meta-analysis of needle exchange program outcome variables related to risky drug and sexual behaviors. Ksobiech's current research efforts are geared toward the creation of HIV risk reduction mediated messages for key risk populations.

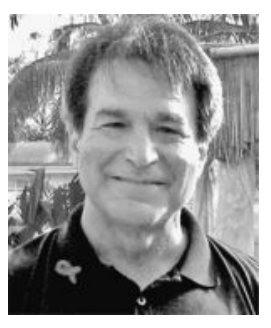

Robert M. Malow, Ph.D, is Professor and Director of the AIDS Prevention Program in the Department of Public Health at Florida International University in Miami, Florida. As a professor in FIU's School of Public Health and the Director of the AIDS Prevention Program, Dr. Malow has pursued adaptation of effective interventions for new and culturally diverse populations, particularly American-born and Caribbean and Latin American immigrants living in South Florida, all of which have been the focus of several federally funded studies. The importance of social networks-relationships with parents, peers, and other kin - and acculturation were integral to one such NIH-funded intervention design for local Haitian-born adolescents. His primary interest has been in developing culturally sensitive intervention designs and well-controlled studies that will reveal the linkages necessary to translate research into practice and to make this technology available to epidemic hot spots, such as the Caribbean region and South Africa. 


\section{Glossary}

Ecological Model

Female

Commercial Sex

Worker (FCSW)

\author{
Situational \\ Alcohol \\ Consumption
}

This model focuses on how social, political, and economic factors as well as features of the social environment interact with personal characteristics to determine health.

Women who engaged in commercial sex-related activity and operating in such venues as beer gardens, bars, nightclubs, karaoke TV centers, massage parlors, or disco dance establishments, where they have become known as indirect sex workers. Sometimes referred to as guest relation officers (GROs) in the Philippines.

Contextual circumstances in which an FCSW and/or her clients are likely to engage in drinking alcohol. Alcohol consumption, by either one or both, takes place immediately before the sexual exchange and occurs when he/she is alone or in the company of the other person.

\section{References}

Abellanosa I, Nichter M. Antibiotic prophylaxis among female bar workers in Cebu City, Philippines: patterns of use and perceptions of efficacy. Sexually Transmitted Diseases. 1996; 23:407-412. [PubMed: 8885073]

Albert AE, Warner DL, Hatcher RA, Trussel J, Bennett C. Condom use among female commercial sex workers in Nevada's legal brothels. American Journal of Public Health. 1995; 85:1514-1520. [PubMed: 7485663]

Auerbach JD, Coates TJ. HIV prevention research: accomplishments and challenges for the third decade of AIDS. American Journal of Public Health. 2000; 90(7):1029-1032. [PubMed: 10897177]

Bandura A. Health promotion by social cognitive means. Health Education Behavior. 2004; 31(2): 143-164. [PubMed: 15090118]

Bhattacharya G. Socio-cultural and behavioral contexts of condom use in heterosexual married couples in India: challenges to the HIV prevention program. Health Education \& Behavior. 2004; 31(1): 101-117. [PubMed: 14768661]

Carlin EM, Boag FC. Women, contraception and STDs including HIV. International Journal of STD and AIDS. 1995; 6(6):373-386. [PubMed: 8845393]

Castro A, Farmer P. Understanding and addressing AIDS-related stigma: from anthropological theory to clinical practice in Haiti. American Journal of Public Health. 2005; 95(1):53-59. [PubMed: 15623859]

Catania JA, Coates TJ, Greenblatt RM, Docini MM, Kegeles SM, Puckett S, Corman M, Miller J. Predictors of condom use and multiple partnered sex among sexually active adolescent women: Implications for AIDS related health interventions. Journal of Sex Research. 1989; 26:514-524.

Catania JA, Kegeles SM, Coates TJ. Towards an understanding of risk behavior: an AIDS risk reduction model (ARRM). Health Education Quarterly. 1990; 17(1):53-72. [PubMed: 2318652]

Celentano D, Akarasewi P, Sussman L, Suprasert S, Mantanasarawoot A, Wright NH, Theetranont C, Nelson KE. HIV-1 infection among lower class commercial sex workers in Chiang Mai, Thailand. AIDS. 1994; 8:533-537. [PubMed: 8011259]

Chesney MA. Factors affecting adherence to antiretroviral therapy. Clinical Infectious Diseases. 2000; 30(Suppl. 2):S171-176. [PubMed: 10860902]

Coates TJ, Collins C. HIV prevention: A 10-point program to protect the next generation against HIV disease. Scientific American. 1998; 279:76-77.

DiClemente RJ, Wingood GM. Expanding the scope of HIV prevention for adolescents: beyond individual-level interventions. Journal of Adolescent Health. 2000; 26(6):377-378. [PubMed: 10822177] 
DiClemente RJ, Wingood GM. Human immunodeficiency virus prevention for adolescents: windows of opportunity for optimizing intervention effectiveness. Arch Pediatr Adolesc Med. 2003; 157(4): 319-320. [PubMed: 12695223]

Du Mont J, McGregor MJ. Sexual assault in the lives of urban sex workers: a descriptive and comparative analysis. Women Health. 2004; 39(3):79-96. [PubMed: 15256357]

Fishbein M. The role of theory in HIV prevention. AIDS Care. 2000; 12:273-278. [PubMed: 10928203]

Fishbein M, Pequegnat W. Evaluating, A.I. DS prevention interventions using behavioral and biological outcome measures. Sexually Transmitted Disease. 2000; 27(2):101-110.

Ford K, Wirawan DN, Fajans P, Meliawan P, MacDonald K, Thorpe L. Behavioral interventions for reduction of sexually transmitted disease/HIV transmission among female commercial sex workers and clients in Bali, Indonesia. AIDS. 1996; 10:213-245. [PubMed: 8838711]

Foreman, M. AIDS and Men: Taking Risks or Taking Responsibility?. Panos/Zed Books; London: 1998.

Hanenberg RS, Rojanapithayakorn W, Kunasol P, Sokal DC. Impact of Thailand's HIV-control programme as indicated by the decline of sexually transmitted diseases. Lancet. 1994; 344(8917): 243-245. 23. [PubMed: 7913163]

Hanenberg R, Rojanapithayakorn W. Changes in prostitution and the AIDS epidemic in Thailand. AIDS Care. 1998; 10:69-79. [PubMed: 9536203]

Ibrahim MA. Editorial: Changing of the Guard. Epidemiologic Reviews. 2004; 26:1.

Kalichman SC, Williams E, Nachimson D. Brief behavioural skills building intervention for female controlled methods of STD-HIV prevention: outcomes of a randomized clinical field trial. International Journal of STD \& AIDS. 1999; 10(3):174-181. [PubMed: 10340198]

Kalichman SC, Weinhardt L, DiFonzo K, Austin J, Luke W. Sensation seeking and alcohol use as markers of sexual transmission risk behavior in HIV-positive men. Annuals of Behavioral Medicine. 2002; 24(3):229-235.

Kelly JA, Murphy DA, Sikkema KJ, Kalichman SC. Psychological interventions to prevent HIV infection are urgently needed. New priorities for behavioral research in the second decade of AIDS. American Psychologist. 1993; 48(10):1023-1034. [PubMed: 8256875]

Kuntolbutra S, Celentano DD, Suprasert S, Eiumtrakol S, Wright NH, Nelson KE. Factors related to inconsistent condom use with commercial sex workers in northern Thailand. AIDS. 1996; 10(5): 556-558. [PubMed: 8724056]

Mateo R Jr. Sarol JN Jr. Poblete R. HIV/AIDS in the Philippines. AIDS Education and Prevention. 2004; 16(3 Suppl. A):43-52. [PubMed: 15262564]

McKirnan DJ, Ostrow DG, Hope B. Sex, drugs and escape: a psychological model of HIV-risk sexual behaviours. AIDS Care. 1996; 8(6):655-669. [PubMed: 8993716]

McLeroy KR, Bibeau D, Steckler A, Glanz K. An ecological perspective on health promotion programs. Health Education Quarterly. 1988; 15(4):351-377. [PubMed: 3068205]

Melkote SR, Muppidi SR, Goswami D. Social and economic factors in an integrated behavioral and societal approach to communications in HIV/AIDS. Journal of Health Communication. 2000; 5(Suppl):17-27. [PubMed: 11010354]

Morisky DE, Ang A, Sneed CD. Validating the effects of social desirability on self-reported condom use behavior among commercial sex workers. AIDS Education and Prevention. 2002a; 14(5):351360. [PubMed: 12413181]

Morisky DE, Chiao C, Stein JA, Malow R. Impact of social and structural influence interventions on condom use and sexually transmitted infections among establishment-based female bar workers in the Philippines. Journal of Psychology and Human Sexually. 2005; 17(1/2):45-63.

Morisky DE, Pena M, Tiglao TV, Liu KY. The impact of the work environment on condom use among female bar workers in the Philippines. Health Education and Behavior. 2002b; 29(4):461-472. [PubMed: 12137239]

Morisky DE, Stein JA, Sneed CD, Tiglao TV, Tempongko SB, Baltazar JC, Detels R, Liu K. Modeling personal and situational influences on condom use among establishment-based commercial sex workers in the Philippines. AIDS and Behavior. 2002c; 6:163-172. 
Morisky DE, Tiglao TV, Sneed CD, Tempongko SB, Baltazar JC, Detels R, Stein JA. The effects of establishment practices, knowledge and attitudes on condom use among Filipina sex workers. AIDS Care. 1998; 10:213-220. [PubMed: 9625904]

Murphy DA, Stein JA, Schlenger W, Maibach E, the National Institute of Mental Health Multisite, HIV Prevention Trial Group. Conceptualizing the multidimensional nature of self-efficacy: assessment of situational context and level of behavioral challenge to maintain safer sex. Health Psychology. 2001; 20:281-291. [PubMed: 11515740]

Mutchler MG. Making space for safer sex. AIDS Education and Prevention. 2000; 12(1):1-14. [PubMed: 10749382]

Nation M, Crusto C, Wandersman A, Kumpfer K, Morrissey-Kane E, Davino K. What works in prevention: principles of effective prevention programs. American Psychologist. 2003; 58:449456. [PubMed: 12971191]

NIAAA Structural RFA. Structural Interventions, Alcohol Use, and Risk of HIV/AIDS. 2004. RFA Number: RFA-AA-05-003. Part I Overview Information. Department of Health and Human Services. Participating Organization: National Institutes of Health (NIH) (http://www.nih.gov/). Component of Participating Organization: National Institute on Alcohol Abuse and Alcoholism (NIAAA/NIH)(http://www.niaaa.nih.gov/)

Nyamathi A, Stein JA, Brecht ML. Psychosocial predictors of AIDS risk behavior and drug use behavior in homeless and drug addicted women of color. Health Psychology. 1995; 14(3):265273. [PubMed: 7641668]

O'Leary, A.; Holtgrave, D.; Wright-DeAguero, L.; Malow, RM. Innovations in approaches to preventing HIV/AIDS: applications to other health promotion activities.. In: Valdiserri, R., editor. Dawning Answers: How the HIV/AIDS Epidemic Has Helped to Strengthen Public Health. Oxford University Press; London: 2003. p. 76-95.

Parkhurst JJ, Lush L. The political environment of HIV: lessons from a comparison of Uganda and South Africa. Social Science and Medicine. 2004; 59(9):1913-1924. [PubMed: 15312925]

Parsons JT, Viciosob K, Kutnick A, Punzalamb JC, Halkkitish PN, Melasqueze MM. Alcohol use and stigmatized sexual practices of HIV seropositive gay and bisexual men. Addictive Behaviors. 2004; 29(5):1045-1051. [PubMed: 15219356]

Pickering H, Todd J, Dunn D, Pepin J, Wilkins A. Prostitutes and their clients: a Gambian survey. Social Science and Medicine. 1992; 34(1):75-88. [PubMed: 1738859]

Poundstone KE, Strathdee SA, Celentano DD. The social epidemiology of human immunodeficiency virus/acquired immunodeficiency syndrome. Epidemiology Review. 2004; 26:22-35.

Pyett PM, Haste BR, Snow J. Risk practices for HIV infection and other STDs amongst female prostitutes working in legalized brothels. AIDS Care. 1996; 8:85-94. [PubMed: 8664372]

Roger, E.; For Opinion Leaders and Diffusion Networks. Diffusion of Innovations. The Free Press; NewYork: 1983. p. 271-311.

Seage GR, Holte S, Gross M, Koblin B, Marmor M, Mayer KH, Lenderking WR. Case-crossover study of partner and situational factors for unprotected sex. Journal of Acquired Immune Deficiency Syndromes. 2002; 31(4):432-439. [PubMed: 12447015]

Sherman SG, Latkin CA. Intimate relationship characteristics associated with condom use among drug users and their sex partners: a multilevel analysis. Drug and Alcohol Dependence. 2001; 64(1):97104. [PubMed: 11470345]

StataCorp. Release 8.0. StataCorp; College Station, TX: 2004. Stata Statistical Software..

Steele CM, Josephs RA. Alcohol myopia. Its prized and dangerous effects. American Psychologist. 1990; 45(8):921-933. [PubMed: 2221564]

Stein JA, Nyamathi A. Gender differences in behavioral and psychosocial predictors of HIV testing and return for test results in a high-risk population. AIDS Care. 2000; 12:343-356. [PubMed: 10928212]

Strecher, VJ.; Rosenstock, IM. The health belief model.. In: Glanz, K.; Lewis, FM.; Rimer, BK., editors. Health Behaviour and Health Education. Jossey-Bass; San Francisco: 1997.

Tan ML. Socio-economic impact of HIV/AIDS in the Philippines. AIDS Care. 1993; 5:283-288. [PubMed: 8218463] 
Tiglao TV, Morisky DE, Tempongko SB, Baltazar JC, Detels R. A community PAR approach to HIV/ AIDS prevention among sex workers. Promotion and Education. 1997; 3:25-28. [PubMed: 9081642]

Tuan, Y-F. Topophilia: A Study of Environmental Perception, Attitudes and Values. Prentice Hall; Englewood Cliffs, NJ: 1974.

UNAIDS. 2006 Report on the Global AIDS epidemic. 2006. http://www.unaids.org/en/HIV_data/2006GlobalReport/default.asp

Variable PA, McKirnan DJ, Buchbinder SP, Bartholow BN, Douglas JM Jr. Judson FN, MacQueen KM. Alcohol use and high-risk sexual behavior among men who have sex with men: the effects of consumption level and partner type. Health Psychology. 2004; 23(5):525-532. [PubMed: 15367072]

Visrutaratna S, Lindan CP, Sirhorachai A, Mandel JS. "Superstar" and "model brothel": developing and evaluating a condom promotion program for sex establishments in Chiang Mai, Thailand. AIDS. 1995; 9:S69-S75. [PubMed: 8562003]

Wee S, Barrett ME, Lian WM, Jayabaskar T, Chan KWR. Determinants of inconsistent condom use with female sex workers among men attending the STD clinic in Singapore. Sexually Transmitted Infections. 2004; 80(4):310-314. [PubMed: 15295132]

Wei SB, Chen ZD, Zhou W, Wu FB, Li SP, Shan JG. A study of commercial sex and HIV/STI-related risk factors among hospitality girls in entertainment establishments in Wuhan, China. Sexual Health. 2004; 1(3):141-144. [PubMed: 16335301]

Weinhardt LS, Carey MP. Does alcohol lead to sexual risk behavior? Findings from event-level research. Annual Review of Sex Research. 2000; 11:125-157.

Wingood GM, DiClemente RJ. Application of the theory of gender and power to examine HIV-related exposures, risk factors, and effective interventions for women. Health Education Behavior. 2000; 27(5):539-565. [PubMed: 11009126]

Zinberg, NE. Drug, Set, and Setting: The Basis for Controlled Intoxicant Use. Yale University Press; New Haven: 1984. 


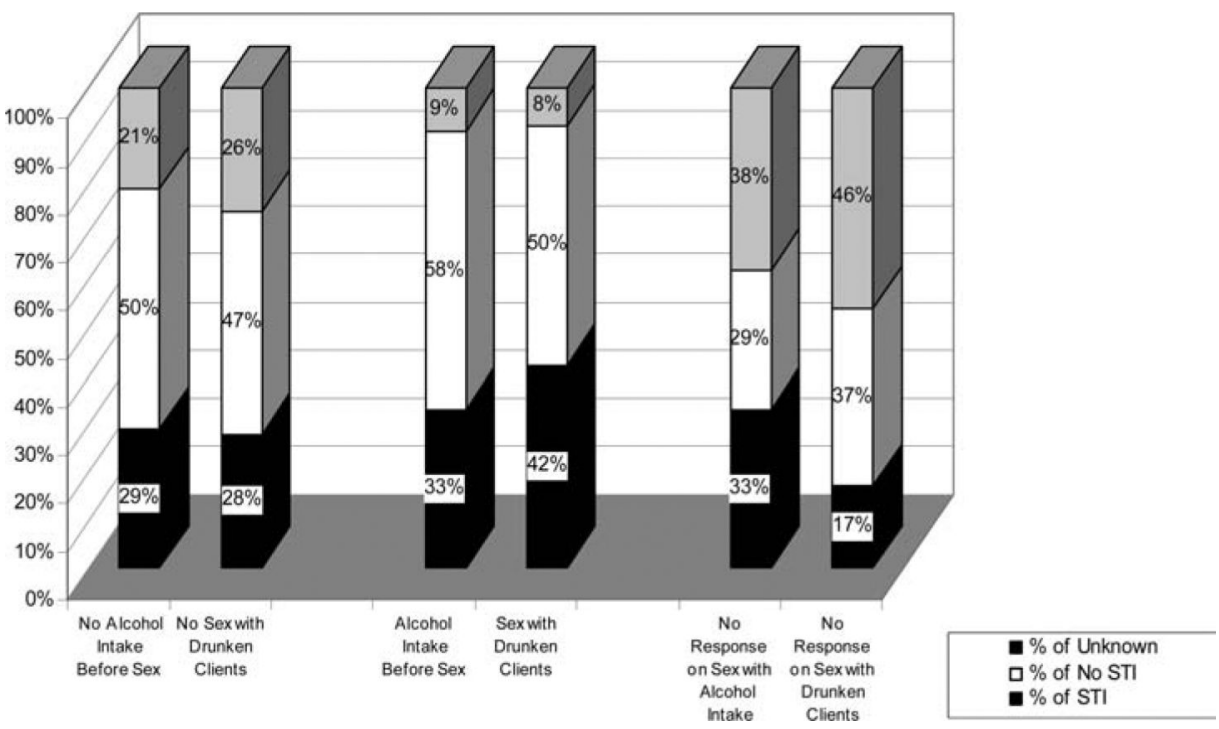

Figure 1.

STI prevalence by alcohol use behaviors with commercial sexual contact, including alcohol intake before $\operatorname{sex}\left(\chi_{(4)}^{2}=72.96 ; p<.01\right)$ and sex with inebriated customers $\left(\chi_{(4)}^{2}=125.36 ; p\right.$ $<.01)$. 
Table 1

Selected characteristics of study sample $(n=1,114)$

\begin{tabular}{|c|c|c|c|}
\hline & Mean & SD & Range \\
\hline Age in years & 23.49 & 5.18 & $15-54$ \\
\hline Education in years & 8.96 & 2.17 & $0-14$ \\
\hline Weekly wage in pesos & $1,237.32$ & $1,158.47$ & $50-9,000$ \\
\hline Length of work in months & 12.47 & 20.30 & $0-240$ \\
\hline Frequency of vaginal intercourse for past week & 1.99 & 3.36 & $0-40$ \\
\hline Frequency of drinking alcohol (1: once or twice a month; 4 : everyday) & 3.06 & .89 & $1-4$ \\
\hline Frequency of drinking alcohol with customers (1: never; 5 : always) & 2.83 & 1.96 & $1-5$ \\
\hline \multirow[t]{2}{*}{ Frequency of drug use (1: never; 5 : always) } & 1.30 & .65 & $1-5$ \\
\hline & $\mathrm{N}(\%)$ & & \\
\hline \multicolumn{4}{|l|}{ Marital status } \\
\hline Single & $571(52 \%)$ & & \\
\hline Single but living with a boyfriend & $215(19 \%)$ & & \\
\hline Separated & $198(18 \%)$ & & \\
\hline Married & $125(11 \%)$ & & \\
\hline \multicolumn{4}{|l|}{ Workplace: } \\
\hline Street worker & $82(8 \%)$ & & \\
\hline Bar-based worker & $744(67 \%)$ & & \\
\hline Non-bar-based worker & $288(26 \%)$ & & \\
\hline \multicolumn{4}{|l|}{ Township } \\
\hline Legaspi & $231(21 \%)$ & & \\
\hline Cagayan de Oro & $378(34 \%)$ & & \\
\hline Cebu & $299(27 \%)$ & & \\
\hline Ilo-Ilo & $206(18 \%)$ & & \\
\hline \multicolumn{4}{|l|}{ STI prevalence in 8 months } \\
\hline No infection & $514(46 \%)$ & & \\
\hline Infection & $345(31 \%)$ & & \\
\hline Unknown status & $255(23 \%)$ & & \\
\hline STI reinfection (\% yes) & $152(14 \%)$ & & \\
\hline Drug injection (\% yes) & $39(4 \%)$ & & \\
\hline \multicolumn{4}{|l|}{ Alcohol intake prior sex } \\
\hline Yes & $215(19 \%)$ & & \\
\hline No & $623(56 \%)$ & & \\
\hline No response & $276(25 \%)$ & & \\
\hline \multicolumn{4}{|l|}{ Sex with an inebriated customer } \\
\hline Yes & $417(37 \%)$ & & \\
\hline No & $490(44 \%)$ & & \\
\hline No response & $207(19 \%)$ & & \\
\hline
\end{tabular}

Percentage may not add up to 100 due to rounding. 
Table 2

\section{Description of measurements}

\begin{tabular}{|c|c|c|}
\hline Variable & Category & Description \\
\hline $\begin{array}{l}\text { Individual sociodemographics } \\
\text { Age }\end{array}$ & Continuous variable measured in years & $\begin{array}{l}\text { Individual socio-demographic characteristics are } \\
\text { derived from Health Belief Model (Strecher and } \\
\text { Rosenstock, 1997) and empirical-based evidence. }\end{array}$ \\
\hline Education attainment & Continuous variable measured in years & \\
\hline Weekly wage & Continuous variable measured in pesos & \\
\hline Length of works & Continuous variable measured in months & \\
\hline \multirow[t]{5}{*}{ Marital status } & Categorical variable with four categories: & \\
\hline & 1. Single & \\
\hline & 2. Single but living with a boyfriend & \\
\hline & 3. Separated & \\
\hline & 4. Married & \\
\hline Alcohol and drug use & & Studies provided empirical evidence for the \\
\hline Frequency of drinking alcohol & $\begin{array}{l}\text { Continuous variable measured by 5-point } \\
\text { Likert scale from "never" (coded as } 1 \text { ) to } \\
\text { "always" (coded as 5) }\end{array}$ & $\begin{array}{l}\text { association between alcohol and drug use and risky } \\
\text { sexual behaviors. }\end{array}$ \\
\hline $\begin{array}{l}\text { Frequency of drinking alcohol } \\
\text { with clients }\end{array}$ & $\begin{array}{l}\text { Continuous variable measured by 5-point } \\
\text { Likert scale from "never" (coded as 1) to } \\
\text { "always" (coded as 5) }\end{array}$ & \\
\hline Frequency of drug use & $\begin{array}{l}\text { Continuous variable measured by } 5 \text {-point } \\
\text { Likert scale from "once or twice a month" } \\
\text { (coded as 1) to "everyday" (coded as 5) }\end{array}$ & \\
\hline Drug injection & $\begin{array}{l}\text { Categorical variable with dichotomous } \\
\text { response (yes/no) }\end{array}$ & \\
\hline Sexual health risks & & Studies provided empirical evidence that \\
\hline $\begin{array}{l}\text { Frequency of vaginal intercourse } \\
\text { for past week }\end{array}$ & $\begin{array}{l}\text { Continuous variable measured in number of } \\
\text { times per week. }\end{array}$ & $\begin{array}{l}\text { engagements of risky sexual behaviors are contingent } \\
\text { to situations (Morisky et al., 2002). }\end{array}$ \\
\hline Likelihood of using condoms & Condom use scale & \\
\hline Condom off inside & $\begin{array}{l}\text { Categorical variable with dichotomous } \\
\text { response (yes/no) }\end{array}$ & \\
\hline HIV/AIDS Practice & & Individual protective health practice and perceived \\
\hline HIV test & $\begin{array}{l}\text { Categorical variable with dichotomous } \\
\text { response (yes/no) }\end{array}$ & $\begin{array}{l}\text { risk varlable is derived from the AIDS risk reduction } \\
\text { model (ARRM) (Catania et al. (1990) and Health } \\
\text { Belief Model (Strecher and Rosenstock, 1997). }\end{array}$ \\
\hline \multicolumn{3}{|l|}{ HIV/AIDS Perception } \\
\hline AIDS perceived risk & $\begin{array}{l}\text { Continuous variable measured by 5-point } \\
\text { Likert scale from "not at all worried" (coded } \\
\text { as 1) to "extremely worried" (coded as 5) }\end{array}$ & \\
\hline Contextual-level factors & & Contextual-level factors are derived from social \\
\hline \multirow[t]{4}{*}{ Workplace } & Categorical variable with three categories: & $\begin{array}{l}\text { ecological theory (McLeroy, et al., 1988; Poundstone } \\
\text { et al., 2004). }\end{array}$ \\
\hline & 1. Street workers & \\
\hline & 2. Bar-based workers & \\
\hline & 3. Non-bar based workers & \\
\hline AIDS education workshop & $\begin{array}{l}\text { Categorical variable with dichotomous } \\
\text { response (yes/no). }\end{array}$ & \\
\hline \multirow[t]{3}{*}{ Township } & Categorical variable with four categories: & \\
\hline & 1. Legaspi & \\
\hline & 2. Cagayan de Oro & \\
\hline
\end{tabular}




\begin{tabular}{ccc}
\hline Variable & Category & Description \\
\hline 3. Cebu & \\
4. Ilo-Ilo & \\
\hline
\end{tabular}




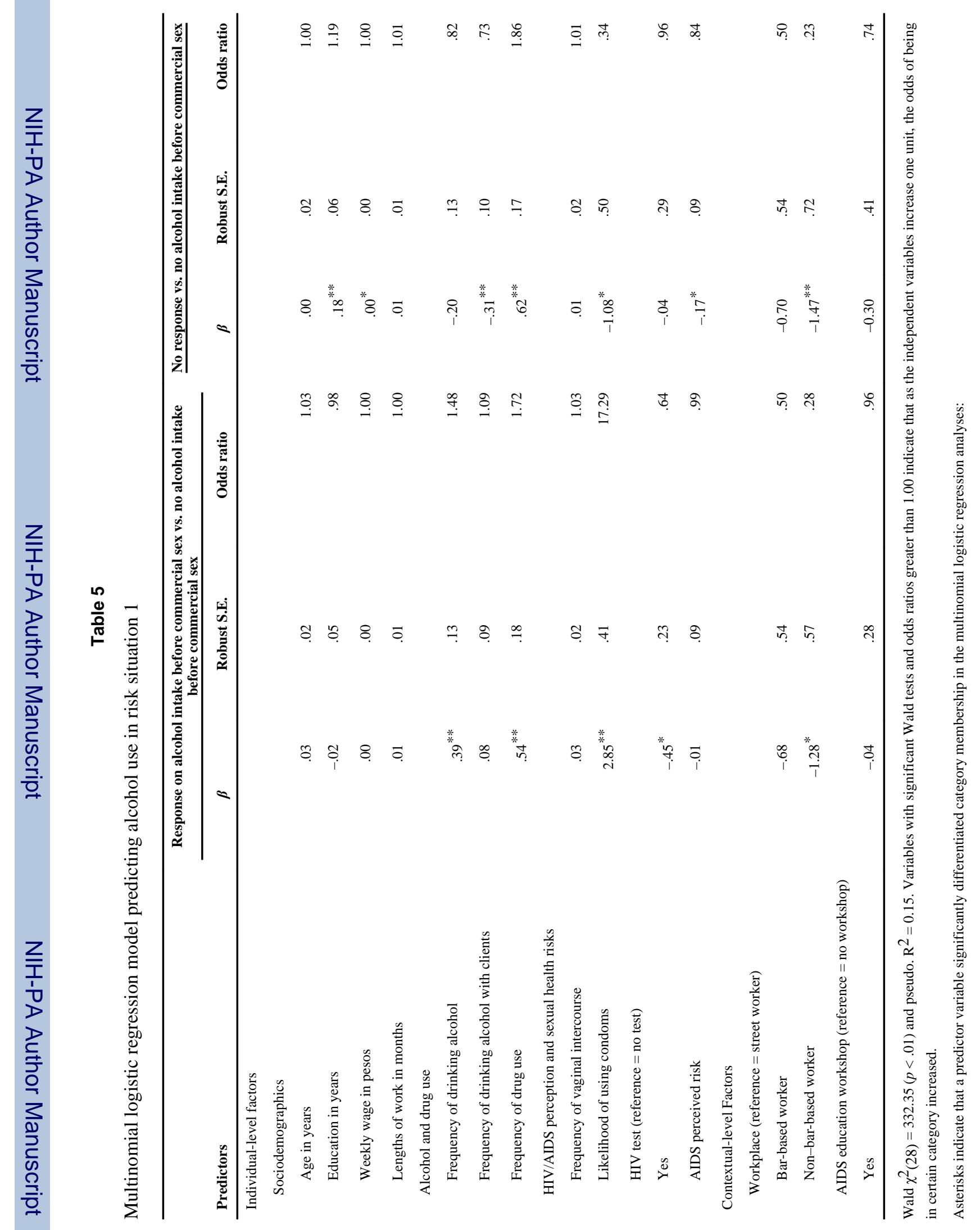




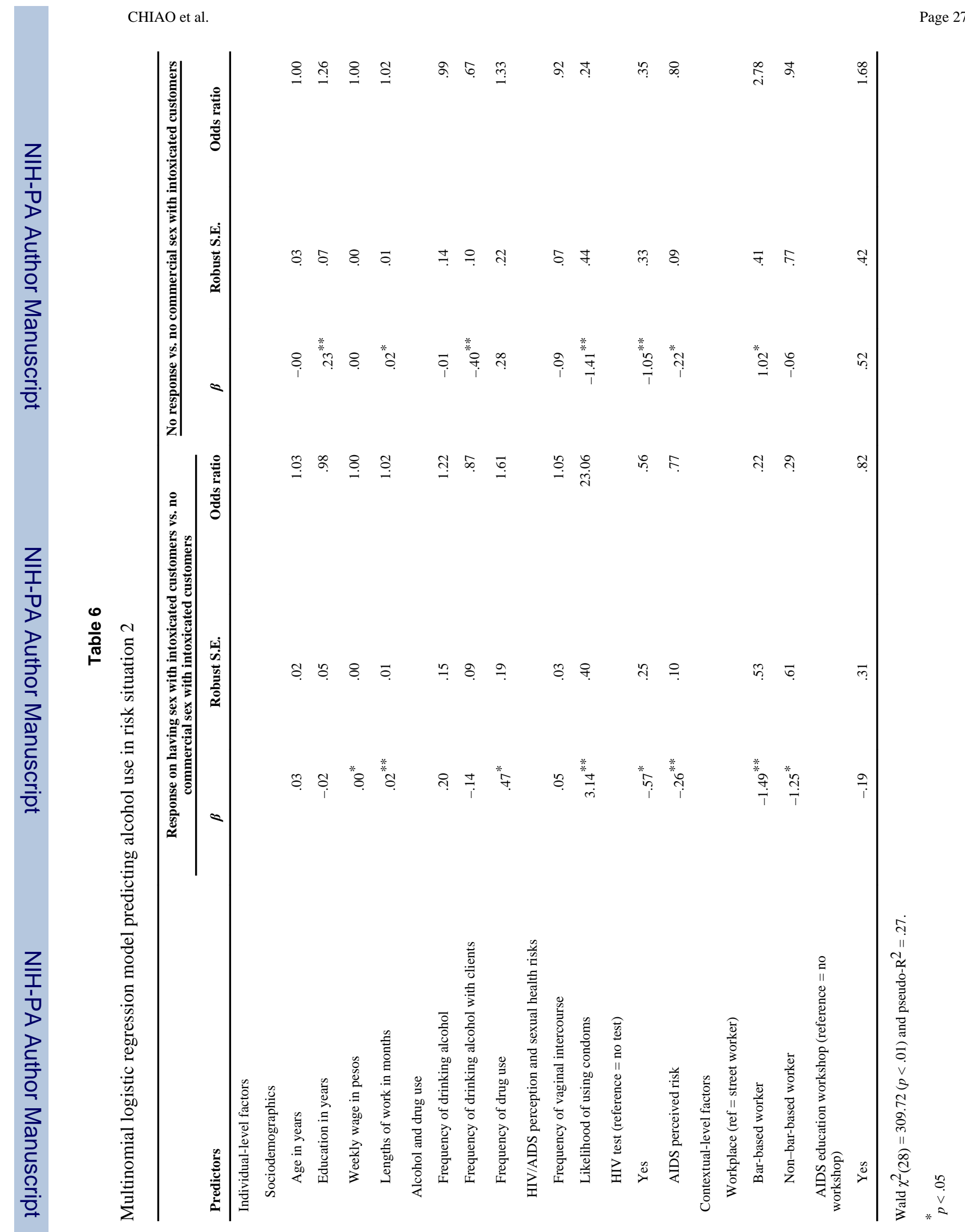

Subst Use Misuse. Author manuscript; available in PMC 2011 May 17. 
